\title{
Illustrations and Figures
}

\author{
MAPS
}

1. The Russian Federation and its internal divisions

2. The Northern Ob River region

PHOTOGRAPHS

1. The Kazym community during the 1991 ethnographic film seminar

2. The Kazym main square, women cooking, 1976

3. Khanty mother and child, in Amnia with a view of Kazym, 1976

4. Khanty boy at Ishyugan fish camp, 1976

5. Tatiana and Timofei Moldanov, Kazym, 1991

6. Khanty artist Nadezhda Taligina, Moscow, 1993

7. Amnia woman on her way to a remembrance feast, 1976

8. Kazym grave with Russian Orthodox cross and sled, 1976

9. Pëtr Moldanov and Franklin Keel, Nulki Lake, Northern Canada, 1996

10. Tegy elder playing the narsus, 1976

11. Bear festival play, ca. 1898-1900. Courtesy of the National Museum of Finland

12. Bear festival dance, ca. 1898-1900. Courtesy of the National Museum of Finland

13. Agrafina Pesikova Sopochina with alligator, Florida, 1998202

14. With Tegy friends, 1976

1. West Siberian demography

2. The Khanty (Ostiak) language as seen by Khanty linguists

3. Tamgi: family and clan signs

4. The ethnicity tree: a view of selected theories 
